ISBN 978-93-84422-79-0

6th International Conference on Humanities, Interdisciplinary Studies, Hospitality and Tourism

Management (HISHTM-17)

Singapore Aug. 10-11, 2017

\title{
Establishment of the Sustainable Management Framework for the Cultural Landscape Resources in Taiwan
}

\author{
Kuei-Yang $\mathrm{Wu}^{1}$ and Shih-Chung Lu ${ }^{2 *}$ \\ ${ }^{1}$ Professor, Department of Architecture, National United University, Taiwan \\ ${ }^{2}$ Assistant Professor, Department of Architecture and Landscape Design, Nanhua University, Taiwan
}

\begin{abstract}
Recently, it becomes a predicament for the cultural landscape issues in Taiwan, and this issue is lack of sustainable management framework. The study tried to recognize the framework of the sustainable management of the cultural landscape and its key factors by using the analytic hierarchy process and the Delphi method. It also discussed the possibility of future policy for center and local government. The main finding was followed: the historical memory plays significant roles to influence the sustainable management of cultural landscape, especially historical exchange, cultural meaning, and settlement. In addition, the cultural feature is also relatively important to influence the framework. However, industrial cultural owned lower scores though it was quite popular in Taiwan.
\end{abstract}

Keywords: Cultural landscape; Sustainable management; Analytic hierarchy process (AHP); Delphi method

\section{Introduction}

Based on the historical and cultural texture, there are lots of cultural landscape resources in Taiwan. However, few cultural resource, such as monuments, was conserved by the limited regulations and management strategies so that they might need the more suitable management model to solve the practical problems, especially the heritage with cultural diversity. Due to the recently coming of damage of cultural landscape by the economic reasons, it is necessary that the cultural landscape development should have more comprehensive plan and problem introspection. Obviously, the sustainable development of cultural landscape cannot be only depended on the current regulations. It was better to find the problems and give the order of conservation under the limited resources, including private or government though the establishment of assessing model.

Although there are a lot of people objections happened for the issues, the governance for the cultural resources in Taiwan seems to be able not to own a main branch to organize the issues, and it also cannot offer a suitable strategy framework toward sustainability. In addition, the Taiwan government offers a lot of costs and resources to protect different cultural landscape, but the strategies were viewed as the local economical ways and political means. Otherwise, the public identification cannot understand the policy and the practical works after the cultural objections. The situation shows there is a large gap existed among public, NGO and the authorities. The gap may product more problems to arrest the policy action and the decision-making. Therefore, the study tried to recognize the framework of the sustainable management of the Taiwan cultural landscape, and its key factors by using the analytic hierarchy process and the Delphi method. It also discussed the possibility of future policy for centre and local government though the framework. 


\section{Material and Methods}

\subsection{The Understanding of AHP}

The Analytic Hierarchy Process (AHP) is a structured technique for dealing with complex decisions. Rather than prescribing a "correct" decision, the AHP helps the decision makers find the one that best suits their needs and their understanding of the problem [1]. Based on mathematics and psychology, it was developed by Thomas L. Saaty in the 1970s and has been extensively studied and refined since then [2]. The AHP provides a comprehensive and rational framework for structuring a decision problem, for representing and quantifying its elements, for relating those elements to overall goals, and for evaluating alternative solutions. It is used around the world in a wide variety of decision situations, in fields such as government, business, industry, healthcare, and education [3].

\subsection{Instrument of AHP}

The study made sure the relative relationship among the influence factors by using literature review and preresearch, and it also confirmed the inter-relationship and framework of sustainable management for cultural landscape by using the expert questionnaires and in-depth interview. The factors in the framework were three levels, including the main goal, level 1, and level 2. Moreover, the level 1 included four parts, local image, environmental identity, historical memory and industrial culture. Then, the factors in the other level was viewed as TABLE 1. Meanwhile, the related experts were chosen, and the amount of the experts for the questionnaires was 22 (including 12 scholars and 10 government members), and the background were wide to cover the different fields in the issues. Through the two-step expert questionnaires, the relative weight has been accounted by using the software, Power Choice, and the results could be put on the framework to assess the potential sustainable strategies.

TABLE 1: The framework of sustainable management for cultural landscape resources in Taiwan

\begin{tabular}{|c|c|c|}
\hline Goal & Lv.1 & Lv.2 \\
\hline \multirow{15}{*}{$\begin{array}{l}\text { Framework of } \\
\text { sustainable } \\
\text { management for } \\
\text { cultural landscape } \\
\text { resources in Taiwan }\end{array}$} & \multirow{4}{*}{ local image } & cultural landscape elements \\
\hline & & religious belief \\
\hline & & local texture \\
\hline & & local narrative \\
\hline & \multirow{4}{*}{ environmental identity } & local identity \\
\hline & & environmental elements \\
\hline & & environmental uniqueness \\
\hline & & cultural features \\
\hline & \multirow{3}{*}{ historical memory } & cultural meaning \\
\hline & & historical exchange \\
\hline & & settlement landscape \\
\hline & \multirow{4}{*}{ industrial culture } & industrial exchange \\
\hline & & industrial facility \\
\hline & & industrial heritage \\
\hline & & industrial landscape layout \\
\hline
\end{tabular}




\section{Results and Discussion}

\subsection{Weight and Importance order of AHP}

The study measured the C.I. and C.R. to resolute the answer steadiness. The result was over the limitation of C.R., and the questionnaire was viewed unavailable sample. Through the accounting of AHP, the weight and the importance were below as TABLE 2:

TABLE 2 The accounting results of AHP

\begin{tabular}{|c|c|c|c|c|c|}
\hline 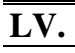 & \multicolumn{2}{|r|}{ Main factors } & Weight & \multicolumn{2}{|c|}{ Importance } \\
\hline \multirow{5}{*}{$\sum$} & \multicolumn{2}{|r|}{ 1. local image } & 0.2170 & \multicolumn{2}{|r|}{3} \\
\hline & \multicolumn{2}{|c|}{ 2. environmental identity } & 0.2450 & \multicolumn{2}{|r|}{2} \\
\hline & \multicolumn{2}{|c|}{ 3. historical memory } & 0.3520 & \multicolumn{2}{|r|}{1} \\
\hline & \multicolumn{2}{|c|}{ 4. industrial culture } & 0.1860 & \multicolumn{2}{|r|}{4} \\
\hline & LV.1 & factors & Weight & $\begin{array}{c}\text { Whole Weight } \\
\text { (Lv.1*Lv.2) }\end{array}$ & $\begin{array}{c}\text { Lv.2 } \\
\text { Importance }\end{array}$ \\
\hline \multirow{15}{*}{$\sum_{i}$} & \multirow{4}{*}{$\begin{array}{l}\text { 1.local image } \\
(0.2170)\end{array}$} & 1.1cultural landscape elements & 0.2520 & 0.055 & 10 \\
\hline & & 1.2 religious belief & 0.2130 & 0.046 & 13 \\
\hline & & 1.3 local texture & 0.2340 & 0.051 & 12 \\
\hline & & 1.4 local narrative & 0.3010 & 0.065 & 5 \\
\hline & \multirow{4}{*}{$\begin{array}{l}\text { 2.environmental } \\
\text { identity }(0.2450)\end{array}$} & 2.1 local identity & 0.2670 & 0.065 & 5 \\
\hline & & 2.2 environmental elements & 0.2300 & 0.056 & 9 \\
\hline & & 2.3 environmental uniqueness & 0.2320 & 0.057 & 8 \\
\hline & & 2.4 cultural features & 0.2710 & 0.097 & 4 \\
\hline & \multirow{3}{*}{$\begin{array}{c}\text { 3.historical } \\
\text { memory }(0.3520)\end{array}$} & 3.1 cultural meaning & 0.3220 & 0.113 & 2 \\
\hline & & 3.2 historical exchange & 0.3640 & 0.128 & 1 \\
\hline & & 3.3 settlement landscape & 0.3140 & 0.111 & 3 \\
\hline & \multirow{4}{*}{$\begin{array}{l}\text { 4.industrial culture } \\
\qquad(0.1860)\end{array}$} & 1.1 industrial exchange & 0.3210 & 0.060 & 7 \\
\hline & & 1.2 industrial facility & 0.2150 & 0.040 & 14 \\
\hline & & 1.3 lindustrial heritage & 0.2940 & 0.055 & 10 \\
\hline & & 1.4 industrial landscape layout & 0.1700 & 0.031 & 15 \\
\hline
\end{tabular}

\subsection{Result and Discussion for Main Factors (Lv.1)}

Based on the results, historical memory $(0.3520)$ is the most important relatively, the second is environmental identity (0.2450), and the followed factors were local image (0.2170) and industrial culture (0.1860) in the Level 1.

From the above result, the historical memory played a key role to influence the sustainable management of cultural landscape. Comparison with the in-depth interview, the historical memory reinforced the cultural landscape base. Therefore, the cultural landscape was not only able to be existed from the practical articles or buildings, and it needed more cultural and historical messages to support the deep meanings.

In addition, the environmental identity and local image were the relatively importances for the issues. The results showed the local specialties were significant for cultural landscape, and the difference was able to increase the sense of identity and public supporting. Higher supporting offered more stable basis to improve the sustainable use of cultural landscape. 
Finally, the industrial culture was relatively weak for the issues. The situation showed few industrial culture was conserved with the huge exchange of industry in Taiwan, so that it was very difficult to resonate for public.

\subsection{Result and Discussion for Sub-Factors (Lv.2) by Main Factors (Lv.1)}

In the Level 2, the sub-factors in the four main factors owned different weight and importance order. Their orders were depended on the main factor weight, because the above factors (Lv.1) were viewed the accounting basis of sub-factors (Lv.2).

From the table 2, there were 15 sub-factors to show their weight, and their above factors made the important coefficient. For the local image (Lv.1), the local narrative (0.3010) played a significant role. Then, the cultural landscape elements (0.2520), local texture (0.2340) and religious belief $(0.2130)$ were owned lower scores. The situation showed the attractive stories was better than others for the promotion of cultural landscape, and it became the main ways to increase the potential benefits of cultural landscape. Therefore, landscape narrative was a trend to encourage emerge of different cultural landscape for a system story, not just a view point. Interestingly, the religious belief was not as important as expected in this issue, even the religious activities in Taiwan owned higher reputation.

In the environmental identity, the cultural features (0.2710) was better than others, local identity (0.2670), environmental uniqueness (0.2320), and environmental elements (0.2300). It meant the cultural features was necessary to support the cultural landscape, and the local identity was as important nearly. The cultural features and local identity were able to create the environmental identity to influence cultural landscape. In addition, environmental elements and uniqueness offered the local features, so that all of them owned very similar weights.

For the historical memory, the historical exchange (0.3640) showed a higher score than others, cultural meaning (0.3220) and settlement landscape (0.3140). It explained the historical exchange was one of the main parts in the historical memory. Furthermore, the memory was accumulated with time, and then the historical exchange, cultural meaning and settlement landscape were as well.

Based on the industrial culture, industrial exchange (0.3210) and industrial heritage (0.2940) owned more scores, so that the inheritance related with local industry offered potentials that the industry enter the cultural fields. Moreover, other factors supported the two main ones.

\subsection{Result and Discussion for Sub-Factors (Lv.2) for Whole Framework}

From the order of the sub-factors, the historical exchange (0.1280), cultural meaning (0.113), and settlement landscape (0.111) were the key factors to influence the whole weight, and the situation gave us a clear guidance to realize cultural landscape. The history was a key to led the cultural aesthetic amenity. Meanwhile, every factor owned historical meanings owned more weight. In addition, the narrative was very important to explanation of culture and history, and it was able to improve the identity and local particularity. Lastly, the industry and religion were not viewed as key factors although they were very important in Taiwanese cultural landscape.

\section{Conclusions}

For the AHP analysis, the historical memory play significant roles to influence the sustainable management of cultural landscape, especially historical exchange, cultural meaning, and settlement. In addition, the cultural feature is also relatively important to influence the framework. However, industrial cultural owned lower scores though it was quite popular in Taiwan.

In Taiwan, there are lots of problems for the cultural landscape management, and it is very serious for uneven allocation of resources. Different principals showed different managing strategies and targets, so that the policy was able to be continued difficultly. The management of the cultural landscape was more important to overcome the problems of conservation of cultural landscape and heritages, and centralization was much more important than decentralization. It was significant to handle the key factors. 
Environmental policy of cultural landscape was not away from public, and the public identity was more relatively important in Taiwan. Therefore, how to make the partnership between public and governance is the key to practice the conflict between conservation and benefit.

\section{Acknowledgement}

This research is supported by the Ministry of Science and Technology, Taiwan. (MOST 105-2410-H-239-010-)

\section{References}

[1] Schelling, T. 1968: The life you save may be your own, In Chase, S. (Ed.), Problems in public expenditure analysis (pp. 143-144). Washinton, D. C.: Brooklings Institution.

[2] Millet, I. \& Harker, P.T. 1990: “Globally Effective Questioning In the Analytic Hierarchy Process", European Journal of Operational Research, Vol. 48, pp.88-97.

[3] Chang, I.S., Yasuhiro Tsujimura, Mitsuo Gen, Tatsumi Tozawa 1995: "An Efficient Approach for Large Scale Project Planning Based on Fuzzy Delphi Method ”, Fuzzy Sets and Systems, 76, 277-288 . 